\title{
Succesful treatment of COVID-19 infection in a child with tracheostomy
}

\author{
Emrah GÜN ${ }^{\mathbf{1}}$ (ID) \\ Edin BOTAN $^{1}($ ID) \\ Halil ÖZDEMIR ${ }^{2}(I D)$ \\ Tanıl KENDiRLi ${ }^{\mathbf{1}}(\mathrm{ID})$
}

${ }^{1}$ Division of Pediatric Intensive Care, Ankara University Faculty of Medicine, Ankara, Turkey

${ }^{1}$ Ankara Üniversitesi Tıp Fakültesi, Çocuk Yoğun Bakım Bilim Dalı, Ankara, Türkiye

2 Division of Pediatric Infectious Diseases, Ankara University Faculty of Medicine, Ankara, Turkey

2 Ankara Üniversitesi Tıp Fakültesi, Çocuk Enfeksiyon Hastalıkları Bilim Dalı, Ankara, Türkiye

To the Editor,

We have read the case report presented by Öz et al.(1) with great interest in Tuberk Toraks journal 2020/68 issue. They reported that a case had dyspnea, fever, and increased tracheal secretions due to coronavirus disease 2019 (COVID-19) infection in a 61 -year-old male patient with tracheostomy. We followed a child case who had similar features. Our case is going to be told in further. COVID-19 infection is thought to have a milder effect in children than adults (2). COVID-19 infection is generally asymptomatic in most children (3). However, children who have comorbid diseases including congenital heart, lung, and airway diseases, malnutrition, tumors, and etc are sensitive to infection with SARS-CoV-2, and they are prone to severe illness if they get COVID-19 (4).

Here, we report a patient who was a 3-year-old male patient with a diagnosis of hydranencephaly and chronic respiratory failure, followed by a home mechanical ventilator for seven months has fever, respiratory distress. He was transferred to our unit from another center after 2 days of follow-up in the pediatric intensive care unit (PICU). When he was admitted to the PICU, his general condition was moderate to poor. His Glasgow Coma Scale was $12 / 15$. As respiratory care, the patient, followed up in the T-tube in the last few months, was connected to a home-type mechanical ventilator due to increased respiratory distress and 


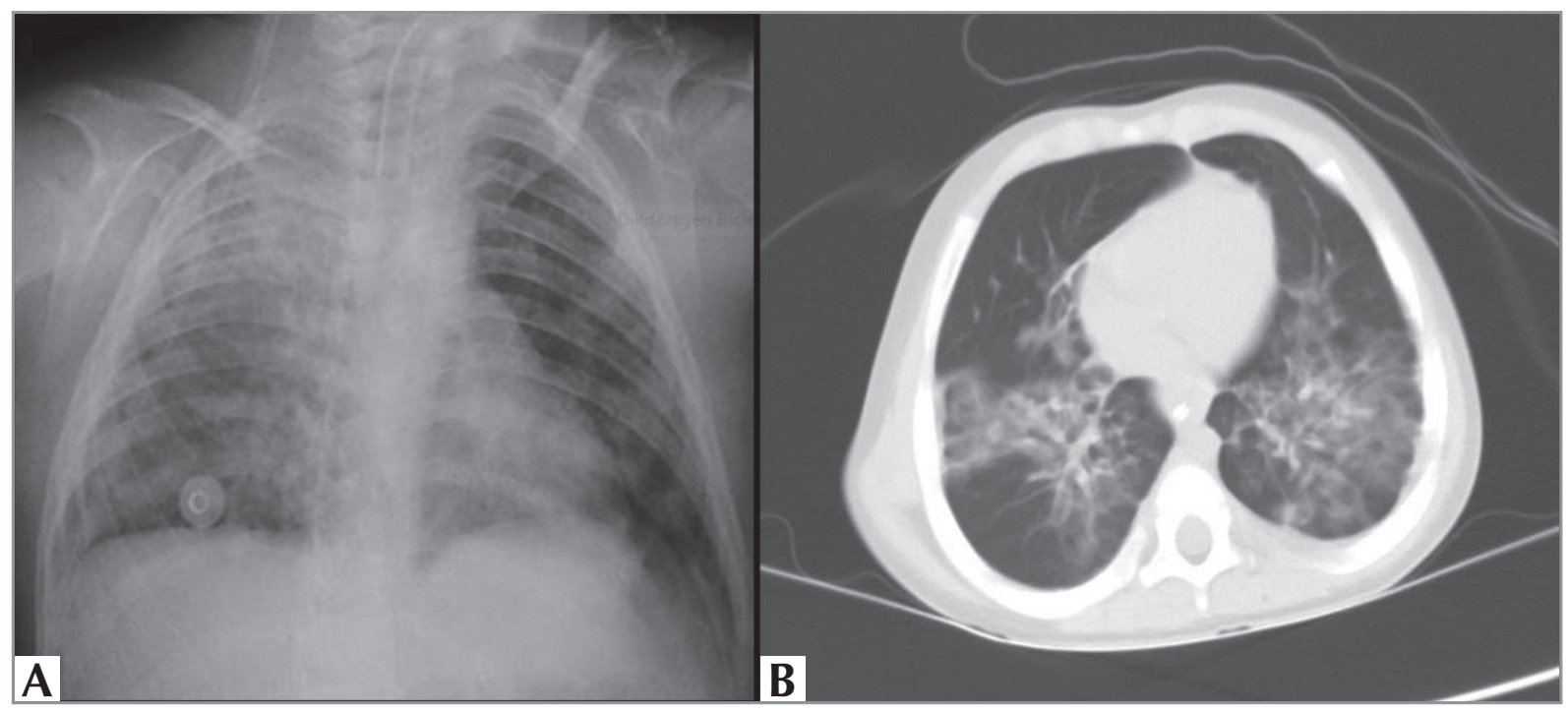

Figure 1. Bilateral infiltration and its more prominent on the right lung on chest X-ray A. Bilateral ground glass-like appearance, and parenchymal infiltration areas accompanied by intra and interlobular septal thickening on thorax computed tomography were seen at patient's radiologic imagines $\mathbf{B}$.

increased tracheal secretions for the last 4 days. He was connected to the mechanical ventilator and was monitored in Pressure-Synchronized intermittent mandatory ventilation (P-SIMV) mode. He had fever, vomiting, shortness of breath, increased tracheal secretions for four days. The patient's body temperature was $38.5^{\circ} \mathrm{C}$, blood pressure was $118 / 75 \mathrm{~mm} / \mathrm{Hg}$, heart rate was $186 / \mathrm{min}, \mathrm{SpO}_{2}$ was $95 \%$. On physical examination, there were bilateral rales in the lungs, and he had tachycardia. Arterial blood gas findings were normal. Laboratory results showed WBC was $17.08 \times 10^{3} / \mu \mathrm{L}$, lymphocyte $6.08 \times 10^{3} / \mu \mathrm{L}, \mathrm{Hb}, 12.3 \mathrm{~g} /$ $\mathrm{dl}$, platelets was $324 \times 10^{3} / \mu \mathrm{L}, \mathrm{CRP} 198 \mathrm{mg} / \mathrm{L}$, PCT $19.16 \mathrm{ng} / \mathrm{mL}, \mathrm{AST}, 133 \mathrm{IU} / \mathrm{L} ; \mathrm{ALT}, 129 \mathrm{IU} / \mathrm{L}$; troponin T, $7.6 \mathrm{pg} / \mathrm{mL}$ (NR: 0-14), NT-pro-BNP, $2072 \mathrm{ng} / \mathrm{L}$, CK-MB $4.82 \mathrm{ng} / \mathrm{mL}$ (NR: 0-3.6), LDH $687 \mathrm{U} / \mathrm{L}$, INR of 1.06, aPTT 37.5, PT 12.4, D-dimer of $422 \mathrm{ng} / \mathrm{mL}$ (NR: 0-243) fibrinogen $3.22 \mathrm{~g} / \mathrm{L}$, (NR: 2-3.93), lipase 203 $\mathrm{U} / \mathrm{L}$, amylase $122 \mathrm{U} / \mathrm{L}$. Intravenous fluid therapy and piperacillin-tazobactam were started. His COVID-19 polymerase chain reaction (PCR) test was positive on admission. In the thorax computed tomography (CT) report of the patient, there was a ground glass-like appearance in the lower lobes of both lungs, the upper lobe of the right lung, the lateral middle lobe of the right lung, and the posterior left upper lobe. Dexamethasone and enoxaparin were started for COVID-19 treatment. His echocardiography was normal. He had abdominal distension and increased amylase and lipase in laboratory results. Abdominal ultrasonography of the patient for pancreatitis was normal. On the second day of hospitalization, Pseudomonas aeruginosa was produced in the tracheal aspirate culture. Antibiotherapy was changed to meropenem and amikacin.

On the $14^{\text {th }}$ day of admission, antibiotic therapy was discontinued, and on the $18^{\text {th }}$ day of the admission, the COVID-19 PCR test was resulted as negative. As respiratory care, patient followed up in P-SIMV mode on the mechanical ventilator, was switched to T-tube on the $20^{\text {th }}$ day. He was discharged on the $32^{\text {nd }}$ day.

Various treatments such as interferon, lopinavir, ritonavir, oseltamivir, azithromycin, and hydroxychloroquine have been trialed for COVID-19 infection in children; however, these treatments are not superior to each other (5). Despite all of these uncertainties, mortality rate in children is low. Mortality rate in children due to COVID-19 has been reported as 5 children $(0.18 \%)$ in a study involving 2843 children (5).

The incidence of lymphopenia in children with COVID-19 is less than in adults, and leukocyte count is usually normal (5). Procalcitonin elevation due to bacterial infection can be seen in these patients (5). Although our patient had severe illness due to COVID-19, lymphocyte count was normal. The leukocyte count and procalcitonin of our patient were high, but it may also be due to concomitant secondary bacterial infection. 
In a patient with tracheostomy, the diagnosis of COVID-19 should not be based solely on reverse transcriptase-polymerase chain reaction analysis of nasopharyngeal/ oropharyngeal (NP/OP) swabs, but lower respiratory tract samples should be evaluated if NP/ OP swabs are negative (1).

In patients with tracheostomy, frequent aspiration of secretion via the tracheostomy cannula suggests lower respiratory tract infection (1). The presence of secondary bacterial infection should be given broad-spectrum antibiotherapy, because secondary bacterial infections may be observed in these patients and worsen the patient's clinic (1).

As a result, although the mortality rate due to COVID-19 is lower in children compared to adults, COVID-19 may be more severe in children with comorbidities, as in our patient. To the best of our knowledge, our patient is the first patient with tracheostomy who was successfully treated for COVID-19.

\section{REFERENCES}

1. Öz M, Gürün Kaya A, Velioğlu Yakut Ö, Gülten E, Talan L, Erol S, et al. Successful treatment of COVID-19 infection in a patient with tracheostomy. Tuberk Toraks 2020; 68(4): 444-8.

2. Patel NA. Pediatric COVID-19: Systematic review of the literature. Am J Otolaryngol. 2020; 41(5): 102573.

3. Munro APS, Faust SN. COVID-19 in children: current evidence and key questions. Curr Opin Infect Dis 2020; 33(6): 540-47.

4. Chao TN, Harbison SP, Braslow BM, Hutchinson CT, Rajasekaran K, Go BC, et al. Outcomes After Tracheostomy in COVID-19 Patients. Ann Surg 2020; 272(3): 181-6.

5. Cui X, Zhao Z, Zhang T, Guo W, Guo W, Zheng J, et al. A systematic review and meta-analysis of children with coronavirus disease 2019 (COVID-19). I Med Virol 2021; 93(2): 1057-69. 